\title{
How discrimination and participation are associated with psychosomatic problems among boys and girls in northern Sweden
}

\author{
Heidi Carlerby ${ }^{*}$, Eija Viitasara, Anders Knutsson, Katja Gillander Gadin \\ Department of Health Sciences, Mid Sweden University, Sundsvall, Sweden; 'Corresponding Author: heidi.carlerby@muin.se
}

Received 6 July 2012; revised 3 August 2012; accepted 14 August 2012

\begin{abstract}
Background: Negative impact on health from school disturbance due to asymmetric power relations such as discrimination and offensive treatment are frequent problems among students. This study sought to analyze associations between occurrence of discrimination at schools, participation and psychosomatic problems. Methods: Pupils in grades 6 - 9 in ten schools in a northern Swedish municipality participated in the study. The frequency of discrimination at school was measured by six items: sex; culture or ethnicity; disability; religion beliefs; sexual preferences; and any other form of discrimination. The Social and Civic Objectives Scale (SCOS) was used for an estimation of the level of participation. The pupils' health was measured by the PsychoSomatic Problem (PSP) scale. Multivariate logistic regression models were used for estimation of increased risk of PSP. The formula $Z=d / s(d)$ was used to test mediation. Results: Two thirds of the boys and three fourths of the girls reported occurrences of discrimination at schools $(p=0.001)$. Discrimination was a mediating factor between participation and PSP among boys and girls as the mediating formula $Z=\mathrm{d} / \mathrm{s}$ (d) was $> \pm 2$ SD, -2.59 for boys and -39.27 for girls. Independent of each other, low participation and discrimination were associated with increased risk of PSP. Conclusion: Discrimination was a mediating factor between participation and PSP. The mediating effect was stronger in girls than in boys. There is a need for school health promotion programs focusing on participation in terms of democratic processes, communication and cooperation in the classroom.
\end{abstract}

Keywords: Discrimination; Participation; Psychosocial School Environment; Psychosomatic Problems Scale; Social and Civic Objective Scale

\section{INTRODUCTION}

Previous studies regarding mental health problems [1] and subjective health complaints show a decrease in pupils' health [2], and this is a challenge for public health work [3]. Swedish researchers [4], e.g. claim that there are interconnections between society, school contextual factors, the pupils' families, the pupils' well-being and their school performance. Similar findings were shown in a Finnish study [2], although the researchers also find associations between health complaints and contextual factors such as bullying, school demands, class spirit and relations to teachers.

Asymmetric power relations, expressed as offensive treatment, are a frequent problem in schools that have negative influence on the psychosocial environment and pupils' health [5-9]. A Portuguese study focusing on mental health among 15 -year-olds in immigrant families showed associations between discrimination and mental ill health such as anxiety and depression in both boys and girls [10]. How discrimination influences adults' health negatively from a number of perspectives has been shown in meta-analytic reviews [11,12] and also in a Swedish study [13]. Discrimination causes stress and stress increases the cortisol level, while also increasing the likelihood of using of health risk behaviors as coping strategies. Examples of such health risk behaviors are smoking and excessively drinking [11]. Wamala et al. (2007) [13] suggest discrimination as a proxy for stress. The Swedish Discrimination Act [14] prohibits discrimination on grounds of sex, cross-over gender expressions, ethnicity, religion or beliefs, disability, sexual orientation and age. These are also the elements against discrimination that form the basis of the Swedish Education Act (Chapter 6) [15]. More specifically, the Swedish Education Act makes distinctions between direct and indirect discrimination, harassment, sexual harassment and other degrading treatment (such as bullying) without specific links to the discrimination elements [7]. The Education Act (Chapter 6) [15] uses the word degrading hen dealing with discrimination in general and refers to the Discrimination Act [14] 
regarding harassment and sexual harassment (Chapter 6) [15]. The flexible use of the discrimination concept in the legal documents makes it complicated to establish a dividing line between the closely related power abuse behaviors discrimination and bullying. Hence, in studies of pupils, bullying needs to be considered even if discrimination is in focus.

A US study among 6th - 12th graders [16] shows how school disturbance and hostile school environments with discriminating behaviors increase the risk of causing avoidant behavior such anxiety and fear. For example, avoidance of certain localities at schools such as toilets, corridors or peripheral parts of the outdoor school environment [16]. A Swedish study of high school girls [17] reports that bullying, sexual harassment and ethnic harassment are regarded as problems at school even if they are not exposed as individuals [17]. In an experimental study [18] pupils in third, fifth and sixth grade and teachers under special education were shown video films with fictive scenes of power demonstration, in this under the term teasing. When the researchers compared the pupils' and teachers' emotional reactions, the researchers came to the conclusion that the teachers really do not know how much harm and hurt the pupils feel in their minds even a long time after witnessing the fictive situation of discrimination. It shows that the feeling of harm and hurt influences the pupils even if they did not experience the power demonstration themselves [18].

A Norwegian study based on fifth, seventh and ninth graders shows that high participation in the class (such as verbal activity and group work) and high teacher support reduce the pupils' feeling of alienation (e.g. reporting the lessons as boring or that the education is worth nothing for their future life) and school distress [19]. That study suggests that there are associations between participatory teaching methods and psychosocial health symptoms [19]. The presence of participation, such as taking part in democratic processes, cooperation in the class and equal weight in communication, has advantages for the pupil's progress, for example decreased bullying and increased social and academic skills [20]. The atmosphere in the class room is important for students' participation and can be measured as school warmth [21]. School warmth illuminates how the students perceive the teachers' engagement, such as supporting the students in a positive manner and listening to the students. Further, the researcher in that study [21] found that participation is a mediating factor between school warmth and the students' academic performance. Participation independently showed significant associations with both school warmth and school performance.

Thus previous research shows that discrimination and bullying are two closely interrelated power demonstrations, that discrimination causes ill health among adults and that participation influences the pupils' health. On the other hand, there is a lack of knowledge regarding whether discrimination is a mediating factor between participation and health. How discrimination in the surrounding environment influences school boys' and girls' participation and health independently of each other has been shown in previous research. We aim to investigate whether children's health is affected in the same patterns as adults' health. This study aimed to analyze associations between the occurrence of discrimination at school, participation and psychosomatic problems among boys and girls in northern Sweden and whether the occurrence of discrimination is a mediating factor.

\section{METHOD}

\subsection{Study Population and Data Collection}

The study includes ten schools in a municipality in northern Sweden. Boys and girls in grades six to nine were invited to answer a web-based questionnaire regarding their health and the psychosocial school environment in January 2011. The pupils answered the questionnaire during ordinary school sessions. Field staff was present during these sessions to answer potential questions and guarantee the integrity of the participants. In total 1527 boys (47.8\%) and girls (52.3\%) answered the questionnaires, which comprised $80 \%$ of the invited pupils. The project was approved by the regional ethical board for human research in Umeå (Dnr: 09-179M) which assured that the study follows the ethical principles for research in accordance with the WHO Helsinki Declaration of 1997 [22].

\subsection{Variables}

The PsychoSomatic Problems (PSP) scale was used to measure health symptoms during the last six months. The scale comprises eight items: suffered from headache, suffered from stomach ache, felt dizzy, had little appetite, felt sad, had difficulty in sleeping, had difficulty in concentrating and felt tense. Each item had five answer options: never, seldom, sometimes, often and always [23]. An index score from 0 to 32 was constructed. The quartile of students with the most PSP was classified as at risk, in accordance with previous studies $[8,23,24]$. The PSP scale has been validated with Rasch analysis and shows adequate fit [25].

The level of participation in the class was measured by the validated instrument [26] Social and Civic Objectives Scale (SCOS) [20]. SCOS comprises eleven questions in three components where students score the atmosphere in the classroom and their classmates' social competence. Each question had six answer options, from "yes absolutely" to "no not at all" and "I do not know". The three 
components were named 1) Democratic competence, (a) standing up for one's opinion, (b) respecting each other's opinions and (c) able to critical review facts (score 3 18); 2) Communication, (a) listening to others' opinions, (b) good at explaining what and how one thinks, (c) expressing one's own opinions in such a way that others listen and (d) participating in most of the discussions during the classes (score 4 - 24); and 3) Cooperation, (a) awareness of the associations between actions and consequences, (b) resolving conflicts in the class, (c) good at cooperation and d) value/appreciate to cooperate (score 4 24) [20]. The single scores of each component were categorized into quartiles and coded as high, middle and low: Democratic competence 4 - 7, 8 - 11 and 12 - 24, Communication4 - 7, 8 - 11 and 12 - 24, Cooperation 4 $7,8-12$ and 13 - 24. Those individuals who were allocated to the high quartile in all three components were used as referents and coded 0 , all others were coded 1. The present study measured the frequency of discrimination at the school during the last six months, with a discrimination index based on six questions (sex, culture or ethnicity, disability, religion or beliefs, sexual orientation and any other form of discrimination). The questions had six answer options (from "never" to "always" plus "I do not know"). The index was dichotomized into never-ever and coded; "never" = 0, "always", "often", "sometimes", "seldom" and "I do not know" = 1 .

Parental background was defined in three subgroups [24,27]. The subgroups were coded as pupils with two Swedish-born parents (Swedish background) $=0$, one Swedish-born and one foreign-born parent (mixed background) $=1$ and two foreign-born parents (foreign background $)=2$. Family structure was defined according to whether the pupils were living with both parents (coded 0 ) or in another family constellation, for example exchange living, living with a single parent or in a stepfamily (coded 1). The relative material affluence was measured with the question "If you consider your situation in the past six months, have you had enough money to be able to do the same things as your friends?" The question had five answer options, "always" and "often" were coded 0 and "sometimes", "rarely" and "never" were coded 1. Grade were coded 6 th $=0,7$ th $=1,8$ th $=2$ and 9 th $=3$.

\subsection{Statistical Analyses}

All the included variables were analyzed by chi-square tests for comparisons of boys and girls. p-values $<0.050$ were considered statistically significant. The logistic regression model included PSP as outcome variable, and discrimination and participation as independent variables. In addition, potential confounding variables were included if the inclusion led to a change of the regression coefficient by more than $10 \%$ [28]. In order to test whether discrimination was a mediator of the association between
Participation and PSP, we used a method suggested by Baron and Kenny (1986) [29]. The formula used for testing the significance of a Z-score was $Z=d / s(d)$, where $d=$ the difference of the regression coefficients between model 1 and model 2 . A Z-score $>2 \pm$ SD was defined as significant [30]. All analyses were performed separately for boys and girls, using SPSS 18.0.

\section{RESULTS}

Table 1 describes the variables and includes chi-square p-values for estimation of differences between boys and girls. The quartile with high PSP comprises two thirds girls and one third boys, which represents $34.9 \%$ of the girls and $16.8 \%$ of the boys in the target population. A majority of the students reported occurrence of discrimination at schools, $68.2 \%$ of the boys and $76.0 \%$ of the girls $(p=0.001)$. Low participation was reported by about two thirds of the boys and by three fourths of the girls ( $p$ $\leq 0.001)$. Nearly two out of ten students reported that they had less money than their friends and around one third of the students were living in other family structures than with two parents. Almost nine percent of the pupils were of mixed background and about five percent were of foreign background.

Table 2 shows increased risk of PSP among boys and girls who have experienced discrimination at school. Increased risk of PSP was also shown among boys and girls with a low level of participation. Discrimination was a mediating factor between low participation and PSP in boys and girls as the $\mathrm{Z}=\mathrm{d} / \mathrm{s}(\mathrm{d})$ was $> \pm 2 \mathrm{SD},-2.59$ for boys and -39.27 for girls. In comparison, the crude ratios and the adjusted ratios for increased risk of PSP only changed moderately. In girls, Model 1 explained 12.2\% of the increased risk of PSP and Model 2 explained 14.4\%. In boys, the corresponding figures were $10.5 \%$ and $12.8 \%$, respectively. Additional findings (not shown in table) were increased risk of PSP among pupils who report that they have less money than their friends, in boys OR $2.55(95 \%$ CI 1.46 - 4.47) and girls OR 2.00 (95\% CI 1.32 - 3.03). An increased risk of PSP was also shown in boys with a mixed background OR 2.94 (95\% CI 1.46 - 5.92). Family structure did not show any increased risk of PSP.

\section{DISCUSSION}

Independently of each other, low participation and discrimination were associated with increased risk of PSP in both boys and girls. This study showed that discrimination was a mediating factor between participation and PSP among boys and girls in northern Sweden.

The present study showed results which are in line with previous research, e.g. a higher proportion of girls than boys are at increased risk of ill health $[1,2,5,8,10,31]$. In line with previous research $[2,13]$, the present study showed 
Table 1. Descriptive statistics in terms of distribution in $\%$ and total number.

\begin{tabular}{|c|c|c|c|c|}
\hline & N 1527 & $\begin{array}{c}\text { Boys } \\
\mathrm{n}(\%)^{\mathrm{a}}\end{array}$ & $\begin{array}{l}\text { Girls } \\
\mathrm{n}(\%)\end{array}$ & $\begin{array}{c}\text { Chi-square } \\
\text { p-value }\end{array}$ \\
\hline & & $728(47.7)$ & $799(52.3)$ & \\
\hline Psychosomatic problems & $\begin{array}{l}\text { No } \\
\text { Yes }\end{array}$ & $\begin{array}{l}595(83.2) \\
120(16.8)\end{array}$ & $\begin{array}{l}512(65.1) \\
275(34.9)\end{array}$ & $<0.001$ \\
\hline Participation & $\begin{array}{c}\text { High } \\
\text { Low and middle }\end{array}$ & $\begin{array}{l}220(36.7) \\
380(63.3)\end{array}$ & $\begin{array}{l}195(27.6) \\
512(72.4)\end{array}$ & $<0.001$ \\
\hline Exposed of discrimination & $\begin{array}{c}\text { Never } \\
\text { Ever }\end{array}$ & $\begin{array}{l}196(31.8) \\
421(68.2)\end{array}$ & $\begin{array}{l}174(23.9) \\
553(76.0)\end{array}$ & 0.001 \\
\hline Parental background & $\begin{array}{l}\text { Swedish } \\
\text { Mixed } \\
\text { Foreign }\end{array}$ & $\begin{array}{c}629(87.6) \\
56(7.8) \\
33(4.6)\end{array}$ & $\begin{array}{c}667(84.1) \\
80(10.1) \\
46(5.8)\end{array}$ & 0.151 \\
\hline As much money as friends & $\begin{array}{c}\text { Always/often } \\
\text { Sometimes/rarely/never }\end{array}$ & $\begin{array}{l}585(80.8) \\
139(19.2)\end{array}$ & $\begin{array}{l}637(80.3) \\
156(19.7)\end{array}$ & 0.816 \\
\hline Family structure & $\begin{array}{l}\text { Living with two parents } \\
\text { Living with step-family/single parent/other }\end{array}$ & $\begin{array}{l}462(63.5) \\
266(36.5)\end{array}$ & $\begin{array}{l}509(63.9) \\
287(36.1)\end{array}$ & 0.845 \\
\hline Grade & $\begin{array}{l}\text { 6th } \\
\text { 7th } \\
\text { 8th } \\
9 \text { th }\end{array}$ & $\begin{array}{l}152(20.9) \\
179(24.6) \\
175(24.0) \\
222(30.5)\end{array}$ & $\begin{array}{l}159(19.9) \\
209(26.2) \\
221(27.7) \\
210(26.3)\end{array}$ & 0.182 \\
\hline
\end{tabular}

${ }^{\mathrm{a}}$ Differences in total n (1527) are due to missing cases; ${ }^{\mathrm{b}}$ Differences estimated by chi-square test shown as p-values.

Table 2. Logistic regression analyses of discrimination as a mediating factor between low participation and PSP in boys and girls, with odds ratio $(\mathrm{OR})$, confidence interval $(\mathrm{CI})$, beta value $(\mathrm{B})$ plus standard error $(\mathrm{SE})$.

\begin{tabular}{|c|c|c|c|c|c|}
\hline Boys & & Crude $^{a}$ & Model $1^{\mathrm{b}}$ & Model 2 & $\mathrm{Z}=\mathrm{d} / \mathrm{s}(\mathrm{d})$ \\
\hline Low and middle participation & $\begin{array}{c}\mathrm{OR}(\mathrm{CI}) \\
\mathrm{B} \\
\mathrm{SE}\end{array}$ & $\begin{array}{c}2.27^{* *}(1.34-3.85) \\
0.819\end{array}$ & $\begin{array}{c}2.18^{* *}(1.25-3.80) \\
0.780 \\
0.282\end{array}$ & $\begin{array}{c}1.98^{*}(1.11-3.54) \\
0.685 \\
0.296\end{array}$ & \\
\hline Exposed of discrimination & $\begin{array}{c}\mathrm{OR}(\mathrm{CI}) \\
\mathrm{B}\end{array}$ & $\begin{array}{c}2.52^{* *}(1.43-4.46) \\
0.925\end{array}$ & & $\begin{array}{c}1.89^{*}(1.02-3.50) \\
0.637\end{array}$ & -2.59 \\
\hline $\mathrm{X}^{2}$ & & & 10.87 & 2.94 & \\
\hline df & & & 8 & 8 & \\
\hline $\mathrm{n}$ & & & 585 & 545 & \\
\hline Nagelkerke $\mathrm{R}^{2}$ & & & 0.105 & 0.128 & \\
\hline Girls & & Crude & Model 1 & Model 2 & $\mathrm{Z}=\mathrm{d} / \mathrm{s}(\mathrm{d})$ \\
\hline Low and middle participation & $\begin{array}{c}\mathrm{OR}(\mathrm{CI}) \\
\text { B } \\
\text { SE }\end{array}$ & $\begin{array}{c}2.46^{* * *}(1.67-3.62) \\
0.898\end{array}$ & $\begin{array}{c}2.37^{* * *}(1.59-3.55) \\
0.864 \\
0.206\end{array}$ & $\begin{array}{c}2.16^{* * *}(1.34-3.28) \\
0.772 \\
0.213\end{array}$ & \\
\hline Exposed of discrimination & $\begin{array}{c}\mathrm{OR}(\mathrm{CI}) \\
\mathrm{B}\end{array}$ & $\begin{array}{c}2.46^{* *}(1.63-3.70) \\
0.899\end{array}$ & & $\begin{array}{c}2.19^{* *}(1.40-3.44) \\
0.784\end{array}$ & -39.27 \\
\hline $\mathrm{X}^{2}$ & & & 5.90 & 15.99 & \\
\hline $\mathrm{df}$ & & & 8 & 8 & \\
\hline $\mathrm{n}$ & & & 690 & 653 & \\
\hline Nagelkerke $\mathrm{R}^{2}$ & & & 0.122 & 0.144 & \\
\hline
\end{tabular}

$\overline{\mathrm{a}^{*}}=\mathrm{p}<0.05 ;{ }^{* *}=\mathrm{p}<0.01 ;{ }^{* * *}=\mathrm{p}<0.001 ;{ }^{\mathrm{b}}$ Models $1 \& 2$ are adjusted for parental background, money enough to be able to do the same things as friends, family structure and grade.

associations between material affluence and ill health. In contrast to previous research that shows increased risk of ill health in girls of foreign background [24], the present study showed increased risk of PSP in boys with a mixed background. Previous research claims that children of mixed parentage are exposed to certain fragility (i.e. lack of natural belonging to a peer group) which might have negative influences on their health [32]. That discrimination can have harmful effects without being experienced by the individuals themselves is shown in previous research [18], which is in line with the present study's findings. The present study's findings that discrimination 
not need to be repeated to have harmful effects on pupils' health is comparable to previous studies [6] showing that single occasions of verbal abuse can have a negative impact on pupils' well-being.

The finding that discrimination functioned as a mediating factor between low participation and increased ill health is supported by previous research [21] which stresses that a sufficiently warm and participant-friendly school environment is one of the most important factors in the children' everyday life. The study by Pridemore (2000) shows that participation is significant for pupil's health outcome, and health promotion needs to have a wholeschool approach [33] in which participation and democracy are the guiding principles [34]. The concept of wholeschool approach includes all actors at school, such as pupils and all professions, the environments at school, for example, the playground, the canteen as well as the classroom [34]. The present study showed results in line with previous research, such as associations between degrading treatment (e.g. bullying) [20] and low participation $[20,35]$ as well as associations between increased risk of ill health and the quality of relations with classmates $[2,9$, $31]$.

As in a Swedish study [17] the present study showed that discrimination occurred in more than half of the schools and that girls are more exposed than boys to expressions of asymmetric power relations. It seems as if the negative health impact of the mediating factor is more pronounced in girls than in boys, as there was a huge difference in the mediating formula $(Z=d / s(d))$ between boys and girls. The higher frequencies of low participation and more PSP in girls probably have their roots partly in constructions of femininities and masculinities. Connell (2009) [36] claims that the construction of gender rules differs in expectations of boys and girls, how a proper woman and a proper man should behave according to normative rules. For example, boys are expected to express their range and power [37], which quite often occurs as discriminating behavior toward their classmates of both sexes $[3,6,7]$. A Swedish focus group study among first- to sixth-graders shows that the school climate was influenced by normalization processes for violence and harassments, such as girls' taking responsibility, boys' dominance strategies, lack of consequences for breaking rules and acceptance of boys' claims for status) [35]. Supportive structures for improved democracy and participation in the school environment make sense for pupils' mental health and well-being [7,9] and have sustainable outcomes such as prevention of youth mortality, reduced smoking and lower alcohol consumption $[3,34]$.

A weakness of the discrimination instrument is that we did not know how to handle the "I do not know" answer option. However, we decided to follow the suggestion by
Ahlström (2009) [26] to look upon "I do not know" as a negative answer and included that answer option in the category of any/some form of perceived discrimination. In contrast to our study where the occurrence of discrimination among boys and girls at school was measured, the study by Wamala et al. (2007) [13] measured perceived discrimination among adults, which made comparisons difficult. One advantage of this study's design is the use of validated instruments, such as SCOS and PSP and the mediating formula [29] to test mediating factors. This combination of instruments resulted in valuable findings which add new knowledge across several disciplines, for example the pedagogical, the sociological and the public health research fields. Further research with an intersectional approach and validated instruments is needed to clarify the interplay between discrimination, participation and PSP.

\section{CONCLUSION}

In conclusion, independently of each other, low participation and discrimination were associated with increased risk of PSP among boys and girls in northern Sweden. Discrimination was a mediating factor between participation and PSP and the mediating effect was stronger in girls than in boys. Boys of mixed background showed increased risk of PSP. Low material affluence was associated with increased PSP in boys and girls, and family structure was not. There is a need for school health promotion programs focusing on democratic processes, communication and cooperation in order to decrease the risk of discrimination and PSP.

\section{ACKNOWLEDGEMENTS}

We would like to thank the boys and girls in elementary schools in the municipality of Östersund for their participation. The project was funded by the Swedish National Institute of Public Health.

\section{REFERENCES}

[1] Hagquist, C. (2010) Discrepant trends in mental health complaints among younger and older adolescents in Sweden: An analysis of WHO data 1985-2005. Journal of Adolescent Health, 46, 258-264.

doi:10.1016/j.jadohealth.2009.07.003

[2] Karvonen, S., Vikat, A. and Rimpelä, M. (2005) The role of school context in the increase in young people's health complaints in Finland. Journal of Adolescents, 28, 1-16. doi:10.1016/j.adolescence.2004.05.006

[3] Srabstein, J. and Piazza, T. (2008) Public health, safety and educational risks associated with bullying behaviors in American adolescents. International Journal of Adolescent Medicine and Health, 20, 223-233. doi:10.1515/IJAMH.2008.20.2.223

[4] Sellström, E. and Bremberg, S. (2006) Is there a "school effect" on pupils outcomes? A review of multilevel studies. Journal of Epidemiology and Community Health, 60, 
149-155. doi:10.1136/jech.2005.036707

[5] Carlerby, H., Viitasara, E., Knutsson, A. and Gådin, K.G. (2012) How bullying involvement is associated with the distribution of parental background and with subjective health complaints among swedish boys and girls. Springer Netherlands, Dordrecht.

[6] Eliasson, M., Laflamme, L. and Isaksson, K. (2005) Verbal abuse, gender and wellbeing at school. International Journal of Adolescent Medicine and Health, 17, 367-378. doi:10.1515/IJAMH.2005.17.4.367

[7] The Swedish National Agency for Education (2009) Discriminated, harassed, offended? Childs, pupil's and students perceptions of discrimination and harassment. Fritzes, Stockholm.

[8] Gådin, G.K. and Hammarström, A. (2005) A possible contributor to the higher degree of girls reporting psychological symptoms compared with boys in grade nine? European Journal of Public Health, 15, 380-385.

[9] Gustafsson, J.E., Westling, A.M., Alin Åkerman, B., Eriksson, C., Eriksson. L., Fischbein, S., et al. (2010) School, learning and mental health: A systematic review. The Royal Swedish Academy of Sciences, The Health Committee, Stockholm.

[10] Neto, F. (2009) Predictors of mental health among adolescents from immigrant families in Portugal. Journal of Family Psychology, 23, 375-385. doi:10.1037/a0015831

[11] Pascoe, E.A. and Smart Richman L. (2009) Perceived discrimination and health: A meta-analytic review. Psychological Bulletin, 135, 531-554. doi:10.1037/a0016059

[12] Williams, D.H., Neighbors, H.W. and Jackson J.S. (2003) Originally published as: Racial/ethnic discrimination and health: Findings from community studies. American Journal of Public Health, 93, 200-208.

doi:10.2105/AJPH.93.2.200

[13] Wamala, S., Bostrom, G. and Nyqvist, K. (2007) Perceived discrimination and psychological distress in Sweden. British Journal of Psychiatry, 190, 75-76. doi:10.1192/bjp.bp.105.021188

[14] SFS 2008:567. The Discrimination Act. Svensk författningssamling. Stockholm.

[15] SFS 2010:800. The Education Act. Svensk författningssamling. Stockholm.

[16] Mayer, M.J. (2010) Structural analysis of 1995-2005 school crime supplement datasets: Factors influencing students' fear, anxiety, and avoidant behaviors. Journal of School Violence, 9, 37-55. doi:10.1080/15388220903153496

[17] Witkowska, E. and Menckel, E. (2005) Perceptions of sexual harassment in Swedish high schools: Experiences and school environment problems. European Journal of Public Health, 15, 78-85. doi:10.1093/eurpub/cki119

[18] Landau, S., Milich, R., Harris, M.J. and Larson, S.E. (2001) You really don't know how much it hurts: Children's and preservice teachers' reaction to childhood teasing. School Psychology Review, 30, 329-343.

[19] Natvig, G., Albrektsen, G. and Qvarnstrøm, U. (2003) Methods of teaching and class participation in relation to perceived social support and stress: Modifiable factors for improving health and wellbeing among students. Educational Psychology, 23, 261-274.

doi:10.1080/0144341032000060101

[20] Ahlström, B. (2010) Student participation and school success: A study about participation, grades and bullying among 9th grade students in Sweden. Education Inquiry, 1, 97-115.

[21] Voelkl, K.E. (1995) School warmth, student participation, and achievement. Journal of Experimental Education, 63, 127-139. doi:10.1080/00220973.1995.9943817

[22] Hermerén, G.R. (2011) Good research practice. The Swedish Research Council's Expert Group on Ethics, Swedish Research Council, Stockholm.

[23] Hagquist, C. (2006) Health inequalities among adolescents - The impact of academic orientation and parents' education. European Journal of Public Health, 17, 21-26. doi:10.1093/eurpub/ck1087

[24] Carlerby, H., Viitasara, E., Knutsson, A. and Gillander Gådin, K. (2011) Subjective health complaints among boys and girls in the Swedish HBSC study: Focussing on parental foreign background. International Journal of Public Health, 56, 457-464. doi:10.1007/s00038-011-0246-8

[25] Hagquist, C. (2008) Psychometric properties of the psychosomatic problems scale: A rasch analysis on adolescent data. Social Indicator Research, 86, 511-523. doi:10.1007/s11205-007-9186-3

[26] Ahlström, B. (2009) Bullying and social objectives: A study of prerequisites for success in swedish schools. Ph.D. Thesis, Umeå University, Umeå.

[27] Vinnerljung, B., Hjern, A., Ringbäck Weitoft, G., Franzén, E. and Estrada, F. (2007) Children and young people at risk. International Journal of Social Welfare, 16, 163-202. doi:10.1111/j.1468-2397.2007.00520.x

[28] Pallant, J. (2007) SPSS Survival manual. McGraw Hill, Open University Press, Berkshire.

[29] Baron, R. and Kenny, D. (1986) The moderator-mediator variable distinction in social psychological research: Conceptual, strategic, and statistical considerations. Journal of Personality and Social Psychology, 51, 1173-1182. doi:10.1037//0022-3514.51.6.1173

[30] Stiles, B., Liu, X. and Kaplan, H. (2000) Relative deprivation and deviantadaptations: The mediating effects of negative self-feelings. Journal of Research in Crime and Delinquency, 37, 64-90. doi: $10.1177 / 0022427800037001003$

[31] Gådin, G.K. and Hammarström, A. (2003) Do changes in the psychosocial school environment influence pupils' health development? Results from a three-year follow-up study. Scandinavian Journal of Public Health, 31, 169177. doi:10.1080/14034940210134121

[32] Fryer, R.G., Kahn. L., Levitt S.D. and Spenkuch, J.L. (2008) The plight of mixed race adolescents. The Review of Economics and Statistics, 94, 621-634. doi:10.3386/w14192

[33] Pridemore, P. (2000) Children's participation in development for school health. Compare, 30, 103-113. doi: $10.1080 / 030579200109888$ 
[34] Wyn, J., Chaill, H., Holdsworth R., Rowling, L. and Carson, S. (2000) Mind matters, a whole-school approach promoting mental health and wellbeing. Australian and New Zealand Journal of Psychiatry, 34, 594-601. doi:10.1080/j.1440-1614.2000.00748.x

[35] Gådin, G.K., Weiner, G. and Ahlgren, C. (2011) School health promotion to increase empowerment, gender equality and pupil participation: A focus group study of a Swedish elementary school initiative. Scandinavian Journal of
Educational Research, 1-17. doi:10.1080/00313831.2011.621972

[36] Connell, R. (2009) Gender. Polity Press, Cambridge.

[37] MacLean, A, Sweeting, H. and Hunt, K. (2010) "Rules" for boys, "guidelines" for girls: Gender differences in symptom reporting during childhood and adolescence. Social Science of Medicine, 70, 597-604. doi:10.1016/j.socscimed.2009.10.042 